\title{
Estimation of Fatigue Lives of Fly Ash Modified Dense Bituminous Mixtures Based on Artificial Neural Networks
}

\author{
Serkan Tapkın* \\ Transportation Engineering Department, Bahçeşehir University, Istanbul 34353, Turkey
}

Received: March 3, 2013; Revised: August 5, 2013

\begin{abstract}
This study deals with estimation of fatigue lives of bituminous mixtures using artificial neural networks. Different types of fly ash were used as filler replacing agents in a dense bituminous mixture. Fatigue tests were performed using repeated load indirect tensile test apparatus under controlled stress conditions. For determination of fatigue life, the initiation of macro crack was accepted as the main criteria to terminate the test. The full-scale tests on asphalt pavement sections are very expensive and these tests require many years in order to be completed and sometimes do not end up with solid conclusions. Therefore, the determination of fatigue lives of bituminous mixtures in the laboratory environment is very important. This study used the experimental data as training set and, with proposed neural network architecture, very reasonable estimates of fatigue lives of bituminous mixtures have been obtained. The proposed approach provides real economy, time saving and allows observing the effect of fly ash replacement and composition on the mechanical properties of mixtures such as fatigue lives and their estimations without carrying out destructive tests.
\end{abstract}

Keywords: fatigue life estimation, fly ash, universal testing machine, dense bituminous mixtures, repeated load indirect tensile test, neural networks

\section{Introduction}

Fatigue in asphalt concrete pavements appears as cracking on the surface of the pavement. Whether it is a highway or an airport pavement, flexible pavements should be designed in such a manner that the amounts of distress or deterioration during the service life are to be minimized. Flexible highway pavements, which are subjected to various types of axle loads and environmental conditions, should be designed adequately in order to be able to achieve the desired performance.

There are numerous models of varying sophistication, which have been developed in order to predict the fatigue behaviour of asphalt concrete including elastic, viscoelastic, elastoplastic, viscoplastic and crack models ${ }^{1}$. One of the keys to obtaining appropriate asphalt mixture properties for use in one model is to use testing modes which induce stress states that are similar to those experienced by the asphalt concrete layer.

The common testing modes used in the laboratory for fatigue evaluation are mainly investigated in a detailed manner in the paper written by Matthews et al. which can be listed below ${ }^{2}$
a) repeated flexure test;
b) direct tension test;
c) diametral repeated load test;
d) dissipated energy method;
e) fracture mechanics test;
f) repeated tension or tension and compression test;
g) triaxial repeated tension and compression test;
h) repeated flexure test on elastic foundation;

i) wheel track test (laboratory); and

j) wheel track test (field).

A fatigue model has also been developed for asphalt mixtures using the elastic-viscoelastic correspondence principle and continuum damage mechanics ${ }^{3}$. Comprehensive field and laboratory studies were carried out in order to characterize the crack growth rate of asphalt mixtures using the Superpave indirect tension tests ${ }^{4}$. Recently, a new method in order to determine the failure of the repeated flexure test was proposed based on the dissipated energy ${ }^{5}$. In addition to the traditional fatigue approach and fracture mechanics approach, damage mechanics is also applied to asphalt mixtures to characterize their fatigue behaviour ${ }^{6}$.

The service life of flexible pavements can be improved by modifying the asphalt mixtures by polymer modifiers. Although application of polymer modifiers is a very effective method to reduce the fatigue cracking, considerable reduction of rut depths and thermal cracking, this solution brings an extra cost in the overall design. In the relevant literature, it was reported that application of fly ash improves the mechanical properties of dense bituminous mixtures ${ }^{7-18}$. Therefore using this waste material in order to improve the mechanical properties of the bituminous mixture provides real economy when compared with polymer modifiers.

Fly ash is finely divided residue of the combustion of pulverized coal. Considerable amounts of fly ash are generated by coal-fired electric and steam generating plants. This waste stream creates a big environmental problem related to handling and storage of this material. Fly ash has been extensively utilized in cement and concrete. There are some other applications of fly ash in highway engineering 
such as soil and road base stabilization, flowable fill, grouts, structural fill and asphalt filler. This study is mainly concerned with application of fly ash as an asphalt filler and prediction of the fatigue life of the asphalt mixtures. The unique spherical shape and particle size distribution of fly ash makes it an effective mineral filler in hot mix asphalt applications. The usage of fly ash as an asphalt filler is still very limited and comprises approximately $0.5 \%$ of overall fly ash application in the construction industry ${ }^{19}$. Use of fly ash in asphalt provides significant advantage over polymer modifiers. Asphalt modification by using polymers is an expensive process and needs skilled workmanship and special equipment. Also, for developing countries, asphalt modification with polymers means more dependence on developed countries for the transfer of technology, know-how, and, most importantly, importation of patented modifiers. The importance of using waste materials, such as fly ash, in the modification of asphalt-aggregate mixtures comes into the scene at this point. Together with the economic considerations, using fly ash in asphalt mixtures alters the mixture behaviour in a very beneficial way ${ }^{17}$. Also, this approach results in a considerable reduction of the volume of coal combustion products that must be disposed in landfills and, at the same time, results in conservation of other natural resources.

There are numerous apparatuses for determination of fatigue life of asphalt ${ }^{2,20}$. The repeated load indirect tensile test is a commonly used tensile test ${ }^{1,17}$. Most of early tests have been reported for concrete or mortar. Currently, this test is applied to cement-treated gravel, lime-soil mixtures and asphalt-stabilized materials. The test involves the loading of a cylindrical specimen with a compressive load applied to two opposite sides. This results in a relatively uniform tensile stress acting perpendicular to and along the diametral plane of the applied load ${ }^{17}$. Finally, a splitting failure is generally occurring along the diametral plane ${ }^{21}$. Under the applied force, perpendicular and horizontal stresses, elastic modulus and strain values can be easily calculated. The reason lying behind the fact of choosing standard Marshall specimens is; these types of specimens can be fabricated in a very easy manner in any pavement laboratory environment through the world. Also these $102 \mathrm{~mm}$ diameter and approximately $63.5 \mathrm{~mm}$ long specimens are very suitable and can be easily tested in any universal testing machine and because of the easiness of the preparation of these specimens, it is possible to test many of them in a reasonable amount of time to arrive at solid conclusions.

The fatigue life can be determined from the reduction of the elastic modulus value to a limiting value, defined as a fraction of the initial value (generally 50\%) or as a number of load repetitions that cause the first crack to arise in the specimen ${ }^{22}$. In this study, the UMATTA tester has been utilized ${ }^{23}$. UMATTA is a testing system that is used to find the elastic modulus, permanent and elastic deformations of Marshall specimens. The system operates automatically and is controlled with the help of a personal computer and software called UMAT. The parameters such as the applied load level, load repetition, the time to reach maximum loading level are given as an input before starting the test. While the test is being carried out, with predefined intervals, the elastic and plastic deformations are recorded and tensile stress, resilient strain, and elastic modulus values are calculated. The experiment is conducted in a temperature-controlled unit and the interior and surface temperature of the specimen is continuously recorded. Based on these experimental results, the fatigue life of asphalt pavements has been modelled in laboratory conditions and extensive tests have been conducted to investigate the effect of fly ash replacement on mixture properties. The aim of these experiments was to model the fatigue or alligator cracking on the pavement structure. With the help of the UMATTA tester, fatigue lives of Marshall specimens have been obtained ${ }^{23}$. The fatigue lives were used as output values and some of the deterministic physical properties of the asphalt mixtures were used as input parameters. By utilizing artificial neural network techniques, the fatigue lives of Marshall specimens were estimated and these values were compared to the actual test results.

\section{Architecture of Artificial Neural Networks}

An artificial neural network is an interconnected group of artificial neurons that uses a mathematical or computational model for information processing based on a connectionist computation approach ${ }^{24}$. In most cases, the artificial neural network is an adaptive system that changes its structure based on external or internal information that flows through the network. In practical terms, the neural networks are non-linear statistical data modelling tools. They can be used to model complex relationships between the inputs and outputs or to find the patterns of data ${ }^{24}$. The power of artificial neural networks in modelling complex relationships between the inputs and outputs is useful for the modelling of the fatigue behaviour of asphalt concrete. Predicting the fatigue life of asphalt concrete based on experimental data is a very important problem. Artificial neural networks can filter out the noise in the experimental data set yet enabling to derive complex relationships and associations. So, this advantage of artificial neural networks has been used in the reported study.

\section{Developing the Artificial Neural Network Model}

In order to develop the artificial neural network model, a very precise and sound data set is required. The artificial neural network modelling consists of two main steps. First, the network has to be trained with the sufficient amount of data obtained in the experiments. There are some important rules that must be followed in the training process ${ }^{24}$. The next step involves the testing of the network with a new data set that was not used in the training process to verify the model. Finally, with developed model, the estimation of asphalt fatigue lives can be performed without carrying out actual laboratory tests. Artificial neural network applications are treated as black-box applications in general. However the studies carried by the author and colleagues in the recent years open this black box and introduces the artificial neural network applications in closed form solutions ${ }^{25-27}$. 
The input variables of the artificial neural network model are some of the deterministic physical properties of the asphalt concrete obtained by the Marshall design. These are bitumen content, specimen height, unit weight of the mixture, the theoretical unit weight of the mixture and total air void values. The reason behind choosing these 5 very "basic" parameters can be explained further as follows. For example, voids in mineral aggregate values (V.M.A.) are scattered in such a limited range that, when further neural network analyses are being carried out, they negatively affect the training performance of the neural network architecture. The same argument is also valid for voids filled with asphalt $\left(\mathrm{V}_{\mathrm{f}}\right)$ values. Also, because of their underperformance effects, it is not suitable to use $V_{f}$ values as an input parameter especially for analyses regarding fly ash replacement. The only output variable is the fatigue life data (cycles to failure) of the Marshall specimens obtained from the repeated load indirect tensile tests. As repeated load indirect tensile test has been chosen as the test method to be applied during the laboratory studies from its applicability and easiness in the simulation of the fatigue cracking in the asphalt layers on site, the above parameters were deemed to be enough for fatigue life estimation. The testing conditions were kept as constant so there was no need to include the temperature, pulse period, loading time, rest period and applied load as input parameters to the neural network architecture. The material properties of the prepared Marshall specimens, which are referring to the geometric and volumetric properties which can very easily be obtained in any laboratory environment, were well enough to characterize the problem inputs. The stiffness or rather any other actual measured parameter is not deemed to be relevant in the neural network analyses as these parameters are "obtained" parameters of the universal testing machine (here UMATTA tester) and if anyone utilizes them in the training and testing procedure of the artificial neural network architecture, the idea lying behind the fatigue life estimation of the asphalt specimens by simple physical material properties fails. The architecture of the proposed artificial neural network model is shown in Figure 1.

In order to prepare the standard asphalt specimens with a diameter of $101.6 \mathrm{~mm}$ and a height of $63.5 \mathrm{~mm}$, Marshall method was utilized by applying 50 blows on each face (which resembles medium traffic conditions). The material properties of these specimens used as the input parameters in the neural network analyses are reported in Figure 1. Before starting the fatigue testing, four different types of fillers (namely 3 different types of fly ash and calcareous filler as reference) were utilized in preparing the sets of Marshall specimens with bitumen contents varying between $2.5 \%$ to $7 \%$ in $0.5 \%$ increments. Therefore, a total of 120 specimens was tested in order to find the optimum bitumen content for different types of filler ${ }^{17}$. Using calculated optimum bitumen contents, new Marshall specimens were prepared with bitumen contents varying between $4.5 \%$ to $6.5 \%$ in $0.5 \%$ increments. Three specimens were prepared for each bitumen content. Therefore, a total of 15 specimens was prepared for each type of fillers. The fatigue lives of these specimens were determined by the UMATTA tester with macro crack initiation criteria as depicted in Figures 2 and 3. As can be visualised in Figure 2, when the control specimen's fail, the fatigue crack is visible to the naked eye. But from Figure 3, the cracks in the specimen's body are in a hairline crack situation (for Soma fly ash modified specimens) and it is very easy to distinguish between the control and fly ash modified specimens. This is an indication of the very positive effect of fly ash modification from pavement engineering point of view. Also in order to be sure whether these cracks are occurring on the visible side of the setup, the back sides of these specimens were also checked by the aid of a simple mirror. These cracks were occurring

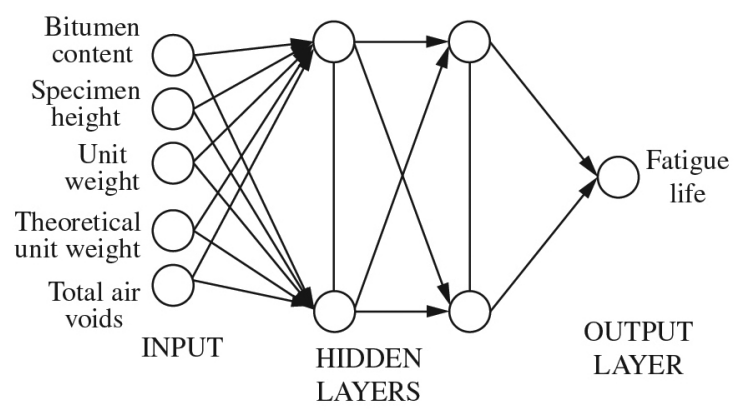

Figure 1. Artificial neural network architecture proposed in the study.

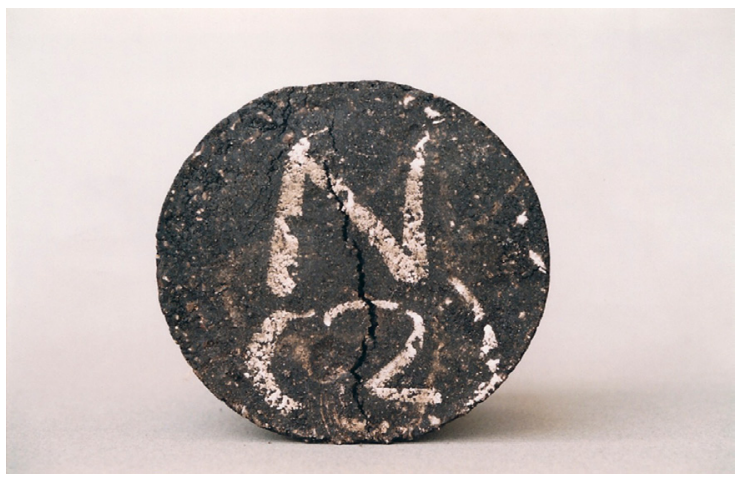

Figure 2. The general view of the control specimen after failure at the end of the carried out repeated load indirect tensile test.

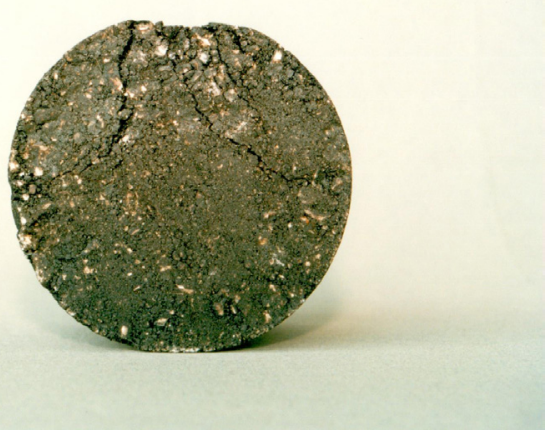

Figure 3. The general view of the Soma fly ash (F type) modified specimen after failure at the end of the carried out repeated load indirect tensile test. 
on both sides approximately at the same pulse counts. The obtained values were used as a training set in the neural network analyses. With the same bitumen content, another similar set of specimens was prepared and tested. The data obtained (cycles to failure, namely fatigue lives) from these 60 specimens were used in the testing of the neural network in order to carry out the simulations in the of neural network toolbox of MATLAB ${ }^{28}$.

\section{Material Properties}

The aggregate gradation used in this study is selected according to the acting standards ${ }^{29}$. Calcareous aggregate was obtained from a native quarry and 60/70 penetration bitumen was obtained from a nearby refinery. The physical properties of these materials are stated in Table 1, 2 and 3. The specimens were prepared in such a way that the filler portion (passing ASTM No.200 sieve) of the selected gradation, given in Figure 4 was replaced by the different types of fly ash in each specimen set. The reason of choosing only single gradation is to analyse the effect of the different types of fly ashes on the mechanical properties of the "dense bituminous mixtures" and to enable a deeper insight to the fatigue life estimation via artificial neural networks. In the asphalt mixtures, three types of fly ash namely Soma ( $F$ type), Çayırhan (F type), Kangal (C type) and calcareous filler (used as reference) were utilized. Such replacement was made solely on a weight basis for practical purposes. Some of the major physical properties of the coarse aggregate and fine aggregate are stated in Tables 2 and 3.

Table 1. Physical properties of the bitumen.

\begin{tabular}{ccc}
\hline Property & $\begin{array}{c}\text { Test } \\
\text { Value }\end{array}$ & Standard \\
\hline Penetration at $25{ }^{\circ} \mathrm{C}, 1 / 10 \mathrm{~mm}$ & 62.0 & ASTM D 5-97 \\
Penetration Index & +1.0 & - \\
Ductility at $25{ }^{\circ} \mathrm{C}, \mathrm{cm}$ & $>100$ & ASTM D 113-99 \\
Loss on heating, $\%$ & 0.053 & ASTM D 6-80 \\
Specific gravity at $25{ }^{\circ} \mathrm{C}, \mathrm{kg} / \mathrm{m}^{3}$ & 1033 & ASTM D 70-76 \\
Softening point, ${ }^{\circ} \mathrm{C}$ & 57 & ASTM D 36-95 \\
Flash point, ${ }^{\circ} \mathrm{C}$ & 257 & ASTM D 92-02 \\
Fire point, ${ }^{\circ} \mathrm{C}$ & 295 & ASTM D 92-02 \\
\hline
\end{tabular}

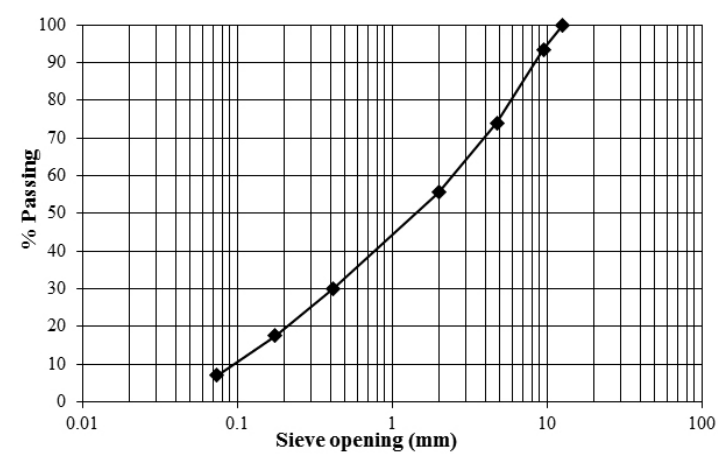

Figure 4. Gradation of the calcareous aggregate.
In the reported study, three different types of fly ash were used as replacement for calcareous filler. Representative specimens of fly ash were obtained from Soma, Çayırhan and Kangal thermal power plants, which are located in different regions of Turkey. The aim of using different types of fly ash is to determine the most suitable type for filler applications in asphalt. This objective was realized by determining the optimum bitumen content (Marshall mix design procedure) and by analysing the fatigue lives of the asphalt specimens with various amounts of bitumen. The oxide compositions (provided by the laboratories of the relevant thermal power plants) of different types of fly ashes are given in Table 4. The physical properties of these fillers are given in Table 5.

The particle size distribution of the filler materials was carried out by Malvern Mastersizer using the dry method ${ }^{30}$. All of the tests were carried at the same laboratory with the same test conditions. The particle size distributions of the fillers are presented in Figure 5.

Table 2. Physical properties of the coarse aggregate.

\begin{tabular}{ccc}
\hline Property & $\begin{array}{c}\text { Test } \\
\text { Value }\end{array}$ & Standard \\
\hline Bulk specific gravity, $\mathrm{kg} / \mathrm{m}^{3}$ & 2754 & ASTM C 127-04 \\
Apparent specific gravity, $\mathrm{kg} / \mathrm{m}^{3}$ & 2821 & ASTM C 127-04 \\
Water absorption, \% & 0.26 & ASTM C 127-04 \\
\hline
\end{tabular}

Table 3. Physical properties of the fine aggregate.

\begin{tabular}{ccc}
\hline Property & $\begin{array}{c}\text { Test } \\
\text { Value }\end{array}$ & Standard \\
\hline Bulk specific gravity, $\mathrm{kg} / \mathrm{m}^{3}$ & 2741 & ASTM C 128-04 \\
Apparent specific gravity, $\mathrm{kg} / \mathrm{m}^{3}$ & 2766 & ASTM C 128-04 \\
Water absorption, \% & 1.43 & ASTM C 128-04 \\
\hline
\end{tabular}

Table 4. Chemical composition of fly ash (FA) samples. (LoI, loss on ignition).

\begin{tabular}{cccc}
\hline Oxide (\%) & $\begin{array}{c}\text { FA Soma } \\
\text { (F Type) }\end{array}$ & $\begin{array}{c}\text { FA Çayirhan } \\
\text { (F Type })\end{array}$ & $\begin{array}{c}\text { FA Kangal } \\
\text { (C Type ) }\end{array}$ \\
\hline $\mathrm{SiO}_{2}$ & 50.48 & 49.74 & 27.92 \\
$\mathrm{Al}_{2} \mathrm{O}_{3}$ & 27.64 & 14.70 & 11.96 \\
$\mathrm{Fe}_{2} \mathrm{O}_{3}$ & 4.80 & 9.04 & 5.14 \\
$\mathrm{SiO}_{2}+\mathrm{Al}_{2} \mathrm{O}_{3}+\mathrm{Fe}_{2} \mathrm{O}_{3}$ & 82.92 & 73.48 & 45.02 \\
$\mathrm{CaO}$ & 13.08 & 13.64 & 37.86 \\
$\mathrm{MgO}$ & 1.30 & 5.10 & 2.60 \\
$\mathrm{SO}_{3}$ & 0.97 & 3.64 & 12.10 \\
$\mathrm{Na}_{2} \mathrm{O}$ & 0.30 & 2.10 & 0.40 \\
$\mathrm{~K}_{2} \mathrm{O}$ & 2.00 & 1.20 & 0.80 \\
$\mathrm{Na}_{2} \mathrm{O}_{\text {eq }}$ & 1.62 & 2.89 & 0.93 \\
$\mathrm{LoI}$ & 1.07 & 2.44 & 3.15 \\
\hline
\end{tabular}


Table 5. Physical properties of mineral fillers.

\begin{tabular}{cccccc}
\hline Physical property & Calcareous filler & Soma fly ash & Çayırhan fly ash & Kangal fly ash & Standard \\
\hline Apparent specific gravity, $\mathrm{kg} / \mathrm{m}^{3}$ & 2632 & 2105 & 2194 & 2525 & ASTM D854-83 \\
Specific Surface Area, $\mathrm{m}^{2} / \mathrm{kg}$ & 322.9 & 249.4 & 242.7 & 277.0 & ASTM C204-00 \\
\hline
\end{tabular}

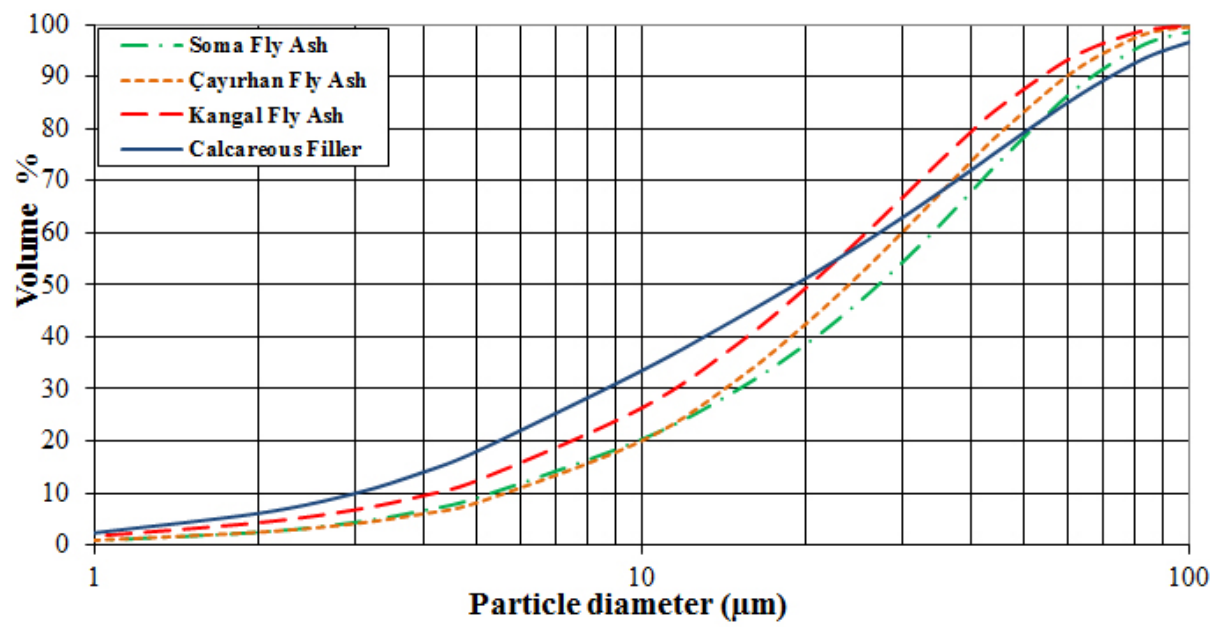

Figure 5. Particle size distributions of fillers.

\section{Asphalt Mixture Design Using Marshall Test Method}

For determination of optimum bitumen content, it is required to perform the Marshall tests and carry out necessary analysis on these test results. Standard Marshall specimens were prepared by applying 50 blows on each face that represents medium traffic conditions. The optimum bitumen content as obtained for different types of filler materials using Marshall designs are given in Figure 6. The optimum bitumen contents were set to provide the maximum stabilities, maximum unit weights, $4 \%$ air voids and $70 \%$ voids filled with asphalt ${ }^{29}$. Besides, all of the Marshall specimens used throughout the fatigue testing have been prepared by utilising $5.0 \%$ bitumen content for the sake of experimental necessities and to obtain a sort of "standard" mixture for comparability purposes (the optimum bitumen content for calcareous filler specimens). The previous studies that have been carried out by the author necessitates this fact in order to be able to work on a sound data basis in order to investigate the fly ash filer replacement's effect on the fatigue life estimation of dense bituminous mixtures ${ }^{17}$.

As it can be seen from Table 5, all three fly ash has approximately equal specific surface area values. The highest specific surface area is off to Kangal fly ash. The highest optimum bitumen content (highest bitumen absorption capacity) value can be expected for this type of fly ash and the test results confirm this fact. As can be seen from Figure 6, the optimum bitumen content of Kangal fly ash is $6.28 \%$, which is the largest of four types of fillers ${ }^{17}$.

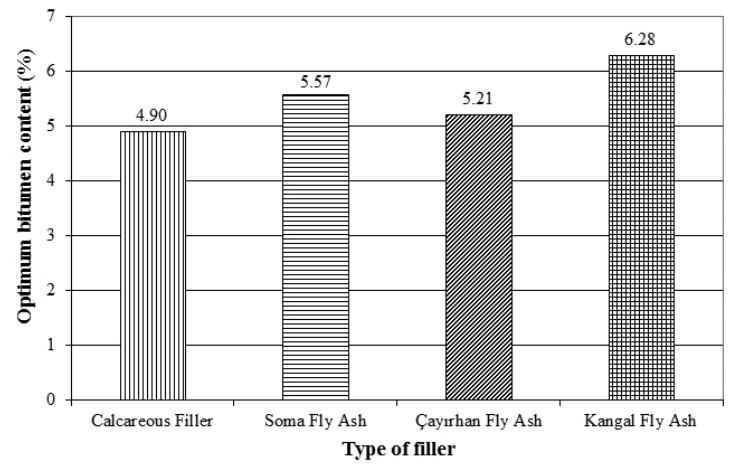

Figure 6. Optimum bitumen contents for different types of mineral fillers.

\section{Fatigue Life Analysis of Marshall Specimens}

There are various approaches for determination of the fatigue life of dense bituminous mixtures ${ }^{1}$. Kim et al. ${ }^{31}$ used $0.25 \mathrm{~cm}$ horizontal deformation as failure criterion. The fatigue life can be determined as the reduction of the elastic modulus value to a limiting value defined as a fraction of the initial value (generally $50 \%$ ) or as the number of load repetitions that cause the first crack to arise in the specimen $^{22}$. The criterion used in the proposed study is the macro crack initiation criterion. That means the fatigue testing was terminated when the crack inititaion has been visible to the naked eye. 
The fatigue life analyses of Marshall specimens were carried out with UMATTA tester ${ }^{23}$. Constant stress indirect tensile fatigue test was carried out at in a temperature controlled cabinet. Test temperature was $40{ }^{\circ} \mathrm{C}$ in order to resemble the in-situ conditions which initiate fatigue cracking in the test carried out in the laboratory environment with UMATTA tester ${ }^{17}$. Although it is known that fatigue cracking occurs at lower temperatures on site, extensive tests were carried out by the researcher in order to be able to simulate the "accelerated conditions" in the temperature controlled cabinet of UMATTA tester. In these previous tests, temperatures between $20^{\circ} \mathrm{C}$ and $40{ }^{\circ} \mathrm{C}$ were utilised but it was impossible to observe the macro cracks although days or maybe weeks of testing periods were exploited especially at temperatures around $20^{\circ} \mathrm{C}^{[31]}$. Therefore $40^{\circ} \mathrm{C}$ was decided as a threshold for the laboratory conditions for fatigue testing in UMATTA tester ${ }^{17}$. In-situ applications point out to the fact that fatigue cracking in asphalt concrete occurs at lower temperatures but when everything suits to the previous research conditions, it is impossible to test this amount of specimens and to arrive at similar results like the ones obtained via the presented study. The reason for choosing a comparatively "higher" ambient temperature of testing is lying through the above discussion. Poisson's ratio was taken as 0.35 . Pulse period was selected as $500 \mathrm{~ms}$. Loading time was chosen as $100 \mathrm{~ms}$, rest period was $400 \mathrm{~ms}$ and the applied load was overridden into system as $1000 \mathrm{~N}$ in all of the experiments.

The repeated load indirect tensile test was carried out in the following manner: the Marshall specimen was placed in the temperature controlled unit for 24 hours prior to testing in order to reach the equilibrium testing temperature. Then the specimen was seated on the loading frame. Lateral deformations of the Marshall specimens arising from repeated indirect loadings were measured by LVDTs (linear variable differential transformer). A load of $1000 \mathrm{~N}$ was applied to the specimen and the elastic and plastic deformations, tensile stress, resilient strain and elastic modulus values were recorded through the data acquisition system and the personal computer. The test was terminated when the initiated crack was visible to the naked eye. This can be seen clearly in Figure 3 .

\section{Repeated Load Indirect Tensile Test Results}

Throughout the testing, the same type of aggregates (gradation curve given in Figure 4), the same type of bitumen (physical properties given in Table 1), the same loading pattern $(1000 \mathrm{~N})$ and the same testing temperature $\left(40{ }^{\circ} \mathrm{C}\right)$ were used. The only difference between the specimens was the type of filler material. A total of 120 specimens was fabricated and tested by using UMATTA tester. The first set of 60 specimens was used to train the neural network (Figure 1) and the second set of 60 specimens was used to test the neural network and obtain the fatigue lives of the Marshall specimens by utilizing artificial neural networks. There is a vast amount of database from the previous studies of the author therefore this 50\% training 50\% testing scheme has been utilised. The specimen type (type of filler), per cent bitumen content, specimen height $(\mathrm{mm})$, unit weight $\left(\mathrm{g} / \mathrm{cm}^{3}\right)$, theoretical unit weight $\left(\mathrm{g} / \mathrm{cm}^{3}\right)$ and average fatigue lives (cycles to failure) are depicted in Table 6. In this table, the depicted figures indicate the average of the three specimens tested. It can be observed that the Soma fly ash specimens have the longest fatigue lives (cycles to failure).

Table 6. Average values of the inputs and outputs used in the training and testing of the neural network (reported as training/testing).

\begin{tabular}{ccccccc}
\hline $\begin{array}{c}\text { Specimen } \\
\text { type }\end{array}$ & $\begin{array}{c}\text { Bitumen } \\
\text { Content }(\%)\end{array}$ & $\begin{array}{c}\text { Specimen Height } \\
(\mathbf{m m})\end{array}$ & $\begin{array}{c}\text { Unit weight } \\
\left(\mathbf{g} / \mathbf{c m}^{3}\right)\end{array}$ & $\begin{array}{c}\text { Theo. Unit } \\
\text { Weight }\left(\mathbf{g} / \mathbf{c m}^{3}\right)\end{array}$ & Total Air V. $(\%)$ & $\begin{array}{c}\text { Fatigue life } \\
(\mathbf{c y c l e s})\end{array}$ \\
\hline Calcareous & $4.5 \%$ & $59.2 / 59.0$ & $2.43 / 2.42$ & $2.43 / 2.53$ & $4.0 / 4.0$ & $42146 / 40647$ \\
Soma & $4.5 \%$ & $61.5 / 61.3$ & $2.33 / 2.31$ & $2.33 / 2.49$ & $6.1 / 6.0$ & $51543 / 49325$ \\
Çayırhan & $4.5 \%$ & $61.6 / 61.3$ & $2.36 / 2.37$ & $2.36 / 2.49$ & $5.0 / 4.9$ & $48154 / 45186$ \\
Kangal & $4.5 \%$ & $63.1 / 62.8$ & $2.28 / 2.29$ & $2.52 / 2.50$ & $9.3 / 9.1$ & $50879 / 47149$ \\
Calcareous & $5.0 \%$ & $59.0 / 58.8$ & $2.41 / 2.40$ & $2.51 / 2.52$ & $3.3 / 3.5$ & $50014 / 52648$ \\
Soma & $5.0 \%$ & $61.3 / 61.0$ & $2.36 / 2.33$ & $2.47 / 2.49$ & $5.0 / 5.1$ & $57296 / 61235$ \\
Çayırhan & $5.0 \%$ & $61.4 / 61.1$ & $2.38 / 2.39$ & $2.48 / 2.48$ & $4.0 / 3.8$ & $53547 / 58332$ \\
Kangal & $5.0 \%$ & $62.8 / 62.5$ & $2.31 / 2.30$ & $2.50 / 2.51$ & $7.8 / 8.0$ & $54218 / 60015$ \\
Calcareous & $5.5 \%$ & $58.9 / 58.8$ & $2.44 / 2.43$ & $2.49 / 2.48$ & $2.1 / 2.3$ & $47149 / 49328$ \\
Soma & $5.5 \%$ & $61.1 / 59.8$ & $2.39 / 2.37$ & $2.45 / 2.46$ & $3.3 / 3.1$ & $62478 / 65837$ \\
Çayırhan & $5.5 \%$ & $61.2 / 60.9$ & $2.41 / 2.42$ & $2.46 / 2.44$ & $2.1 / 2.0$ & $51687 / 53117$ \\
Kangal & $5.5 \%$ & $62.5 / 62.1$ & $2.34 / 2.36$ & $2.49 / 2.50$ & $5.6 / 5.8$ & $57258 / 54956$ \\
Calcareous & $6.0 \%$ & $58.7 / 58.6$ & $2.45 / 2.44$ & $2.48 / 2.44$ & $1.5 / 1.7$ & $46387 / 44724$ \\
Soma & $6.0 \%$ & $61.0 / 59.7$ & $2.39 / 2.40$ & $2.44 / 2.41$ & $2.5 / 2.4$ & $55794 / 51249$ \\
Çayırhan & $6.0 \%$ & $61.0 / 60.7$ & $2.39 / 2.42$ & $2.45 / 2.48$ & $1.4 / 1.5$ & $47228 / 45332$ \\
Kangal & $6.0 \%$ & $62.0 / 61.7$ & $2.38 / 2.36$ & $2.47 / 2.46$ & $4.0 / 4.1$ & $59514 / 61228$ \\
Calcareous & $6.5 \%$ & $58.5 / 58.4$ & $2.44 / 2.41$ & $2.46 / 2.45$ & $0.9 / 1.0$ & $44526 / 46619$ \\
Soma & $6.5 \%$ & $60.8 / 59.5$ & $2.38 / 2.43$ & $2.42 / 2.43$ & $1.7 / 1.9$ & $53861 / 55426$ \\
Çayırhan & $6.5 \%$ & $60.8 / 60.5$ & $2.37 / 2.36$ & $2.43 / 2.43$ & $0.7 / 0.9$ & $44197 / 42687$ \\
Kangal & $6.5 \%$ & $61.6 / 61.3$ & $2.33 / 2.30$ & $2.44 / 2.45$ & $2.1 / 2.4$ & $52867 / 50237$ \\
\hline
\end{tabular}


Kangal fly ash specimens have the second longest fatigue lives, Çayırhan fly ash specimens the third and finally calcareous filler (reference) specimens have the shortest fatigue lives ${ }^{17}$. Figure 6 shows that the pattern of the fatigue lives of Marshall specimens exhibits a very good correlation with the optimum bitumen content values.

Although some of the air void contents of the Marshall specimens prepared by using different types of fly ash are above 5\% (the main departure from the General Directorate of Turkish Highways' standards), these specimens were tested in order to determine their fatigue lives. These mixes performed well in the fatigue tests when compared with calcareous filler specimens (Table 6). Under the effect of high tire pressures and high axle loads of the heavy vehicles, the flushing and bleeding problems frequently occur and so, especially at high ambient temperatures, the use of fly ash as a filler replacing agent is very effective. On the other hand, high air void values permit for lower compaction temperatures when laying asphalt on $\operatorname{site}^{32}$. Also, good resistance to rutting, prolonged fatigue life (as evidenced in the present study) and less reflection cracking can be achieved due to application of fly $\operatorname{ash}^{33}$.

In this study, the tests had been terminated at the point when the first visible crack was seen on the specimen surface. Therefore, the fatigue lives were calculated on this basis. The Soma fly ash specimens have exhibited approximately $25 \%$ longer fatigue lives compared to calcareous filler specimens as it can be seen from Table 6. Kangal and Çayırhan fly ash specimens have shown approximately $18 \%$ and $9 \%$ longer fatigue lives compared to those of the calcareous filler specimens. Soma fly ash specimens perform better than other types of fillers due to ${ }^{17}$ :

a) Soma fly ash (class F) is the coarsest fly ash; therefore, it provides the stiffening effect arising from the fillerbitumen interaction.

b) The aluminium oxide $\left(\mathrm{Al}_{2} \mathrm{O}_{3}\right)$ percentage of Soma fly ash specimens is $27.64 \%$ which is more than twice that of the other two types. The aluminium oxide is considered to be responsible for the better bond, and therefore, improved strength and stiffness of the Marshall specimens. The improvement in strength and stiffness of the Marshall specimens arises from the increase of the bond between the aggregate and binder which was concluded from the previous studies of the corresponding author ${ }^{17}$.

c) The apparent specific gravity of Soma fly ash is $2105 \mathrm{~kg} / \mathrm{m}^{3}$, which is the smallest of the three types of fly ashes. Also, this value is much smaller than the specific gravity of the calcareous filler. Therefore, it can be concluded that the filler-bitumen paste of Soma fly ash specimens shows better "bitumen extension" (better compatibility of bitumen and fly ash) when compared with the specimens prepared with other types of fly ashes ${ }^{17}$.

\section{Test Results and Discussion}

The actual fatigue tests (repeated load indirect tensile tests) on Marshall specimens in the laboratory environment are time consuming. To give a representative value, a fatigue test continuing for 50000 cycles approximately lasts in 7 hours under the test conditions of the proposed study. This is a relatively long time although the repeated load indirect tensile tests carried out in the laboratory are accepted as "accelerated". In order to be able to make reasonable estimates regarding the fatigue lives of the Marshall specimens, the material properties depicted in Figure 1 were used as the input parameters for the neural network architecture. Based on the characteristics of the data set obtained through extensive laboratory testing, a learning algorithm involving a forward-propagating step by a backward-propagating step (feed-forward backpropagation) has been involved. The only output parameter considered in this study is the fatigue life $\left(\mathrm{N}_{\mathrm{f}}\right)$ measured by the UMATTA tester. The training and testing processes are performed by using the neural network toolbox of $\mathrm{MATLAB}^{28}$. In almost all of the neural models that are used to approximate functions by utilizing back-propagation model, one hidden layer is deemed to be sufficient ${ }^{24}$. But for the research purposes, two and three hidden layers were also utilized while determining the optimum architecture. The number of hidden nodes in the hidden layers was determined by adaptive training and on-line monitoring of accuracy measures on the testing data sets. This was done by varying the number of hidden processing elements, in the hidden layer, until the network was able to learn the patterns involved in the test data sets. Hidden nodes varying between 5 and 50 (increasing by multiples of 5) have been tried in order to find the optimal architecture. After carrying out several trials with the neural network toolbox of MATLAB ${ }^{28}$, it has been concluded that, the most stable results from the point of view of predicted fatigue life cycles have been obtained by utilising 20 hidden neurons in the hidden layers

The mathematical activation function has been chosen as logarithmic-sigmoid, which produces values typically in the range of 0 to 1 . In order to be able to utilize this type of activation function, the input data were normalized. The gradient descent algorithm was used in the training of the back-propagation model. Some different techniques have been used to accelerate the convergence of gradient descent techniques ${ }^{24}$. In this study, the Levenberg-Marquardt training algorithm has been used. With the help of this algorithm, very reasonable and fast simulation results can be obtained as training the neural networks takes several hours with ordinary gradient descent algorithm. The aim of using artificial neural networks is to save the time in laboratory testing and utilization of Levenberg-Marquardt algorithm was beneficial.

Ranges of experimental results are given in Table 7 . The testing (\% 50) and training (\%50) sets for neural network training procedure are selected randomly from the experimental database as the author has been utilising the same similar aggregate and bitumen resource for many years well spanning the study's test period. The optimal neural network architecture was found to be 5-20-1 (20 hidden neurons) as shown in Figure 1.

The next step is to test the network with a unique data set that was not used in the training process. While testing the network, the experimental fatigue lives are compared with the fatigue lives obtained by artificial neural network 
Table 7. Ranges of experimental database.

\begin{tabular}{ccccccc}
\hline & $\begin{array}{c}\text { Bitumen content } \\
(\boldsymbol{\%})\end{array}$ & $\begin{array}{c}\text { Specimen Height } \\
(\mathbf{m m})\end{array}$ & $\begin{array}{c}\text { Unit Weight } \\
\left(\mathbf{g} / \mathbf{c m}^{\mathbf{3}}\right)\end{array}$ & $\begin{array}{c}\text { Theo. Unit Weight } \\
\left(\mathbf{g} / \mathbf{c m}^{\mathbf{3}}\right)\end{array}$ & $\begin{array}{c}\text { Total Air V. } \\
(\boldsymbol{\%})\end{array}$ & $\begin{array}{c}\text { Fatigue life } \\
(\mathbf{c y c l e s})\end{array}$ \\
\hline Max & 6.5 & 63.3 & 2.49 & 2.56 & 9.6 & 66142 \\
Min. & 4.5 & 58.1 & 2.25 & 2.3 & 0.68 & 23211 \\
Mean & 5.5 & 60.69 & 2.38 & 2.46 & 3.65 & 50899.73 \\
Std. Dev & 0.72 & 1.37 & 0.05 & 0.04 & 2.28 & 7620.21 \\
\hline
\end{tabular}

simulations. This comparison is performed on a Root Mean Squared Error (RMSE) basis. RMSE values can be obtained by the following standard formula:

$\operatorname{RMSE}=\sqrt{\frac{\sum_{\mathrm{j}=1}^{\mathrm{n}}\left(\mathrm{X}_{\mathrm{j}}-\mathrm{X}\right)^{2}}{\mathrm{~N}}}$

where: $\mathrm{N}=$ total number of observations; $\mathrm{X}_{\mathrm{j}}=$ predicted values; $\mathrm{X}=$ observed values.

The main objective was to fit the most suitable model for the prediction of fatigue lives of different types of specimens. The criterion for determining the network topology with the "best" performance which validates the simulation results in a best manner is having a network that has the smallest RMSE and, in addition, having the highest coefficient of determination $\left(\mathrm{R}^{2}\right)$ for observed versus predicted (simulated) data.

Hidden neuron numbers varying between 5 and 50 have been used through the training sessions. In order to determine the optimal hidden layer number, neural network architectures with one, two and three hidden layers were trained and tested. The activation function has been chosen as logarithmic-sigmoid after several trials have been carried out with other activation functions such as tangent-sigmoid ${ }^{34}$. The termination criteria or goal achievement is set to $10^{-6}$. Finally minimum gradient, which is another termination criteria used in correspondence with goal achievement, is $10^{-10}$. The corresponding RMSEs and $\mathrm{R}^{2}$ values are depicted in Table 8 for one, two and three hidden layers, respectively. These values are obtained statistically by analysing the predicted results together with the actual testing results of 120 different Marshall specimens (Table 6).

The obtained RMSE values show that the proposed architecture of one hidden layer comprising of 20 hidden processing elements converged to the smallest standard error. In addition, the architecture with one hidden layer had the highest coefficient of determination. Figures 7 to 9 show the scattergrams depicting the observed versus predicted fatigue lives for one, two, and three-hidden layer backpropagation neural network topologies. The ideal shape in all scattergrams would have been a straight line with a slope of 45 degrees that crosses the origin (Figures 7 to 9). All graphs, however, show minor deviations from the ideal, but it is evident that the one-hidden-layer back-propagation neural network gives the "best" performance. Table 8 indicates that for the optimum number of processing elements (that is 20 hidden neurons in all of the hidden layers), increasing the number of hidden layers results in a reduction in the overall model performance. This reduction is approximately $37 \%$ in RMSE basis and $4 \%$ in $\mathrm{R}^{2}$ basis between one and three
Table 8. The prediction performances of back-propagation neural network architectures.

\begin{tabular}{ccc}
\hline $\begin{array}{c}\text { Neural Network } \\
\text { Architecture }\end{array}$ & RMSE Value & $\mathbf{R}^{\mathbf{2}}$ Value \\
\hline One hidden layer & 1928.7 & 0.925 \\
Two hidden layers & 2465.8 & 0.902 \\
Three hidden layers & 2643.9 & 0.891 \\
\hline
\end{tabular}

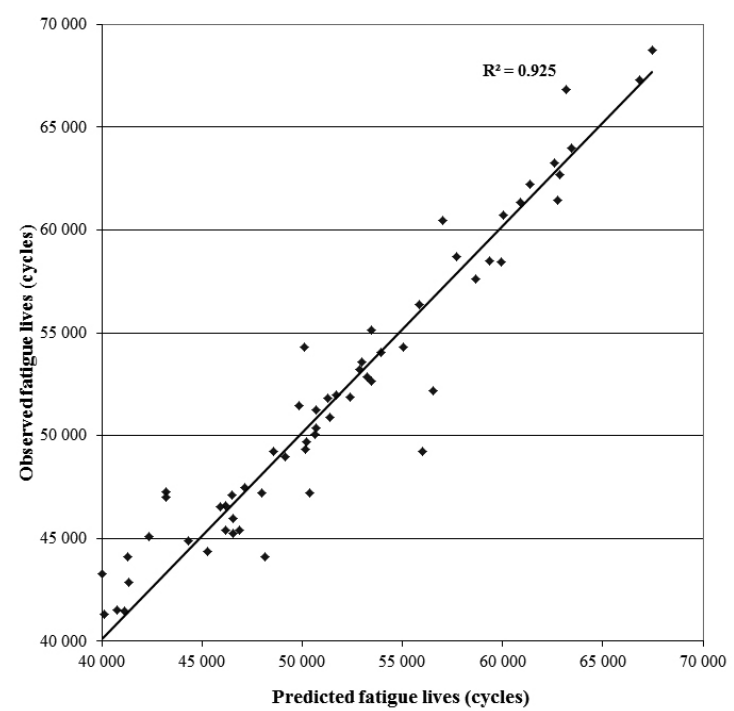

Figure 7. Scattergram of fatigue life prediction model with onehidden layer.

hidden layer architectures. This suggests that a one-hidden layer back-propagation neural network is sufficient for fatigue life prediction and increasing the number of hidden layers does not add any benefit to the proposed model performance ${ }^{24}$.

\section{Conclusions and Further Recommendations}

This paper examined the effect of fly ash as a filler replacing agent on mechanical properties of bituminous mixtures. The utilisation of this material will arise a very important benefit for the waste management industry all over the world. The artificial neural networks were used to estimate the fatigue lives of investigated mixtures. According to the extensive testing, Soma fly ash specimens had the longest fatigue lives. The Soma fly ash (F type) specimens have exhibited approximately $25 \%$ longer fatigue 


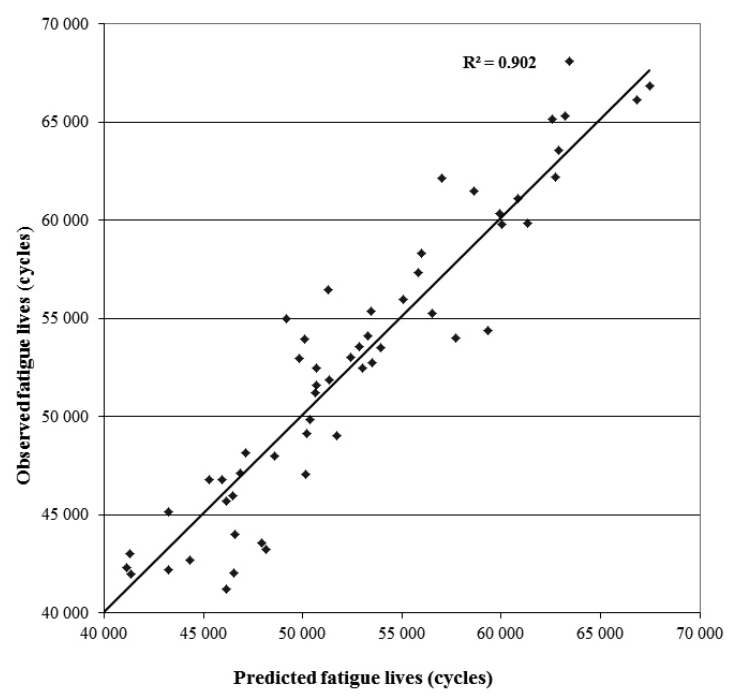

Figure 8. Scattergram of fatigue life prediction model with twohidden layers.

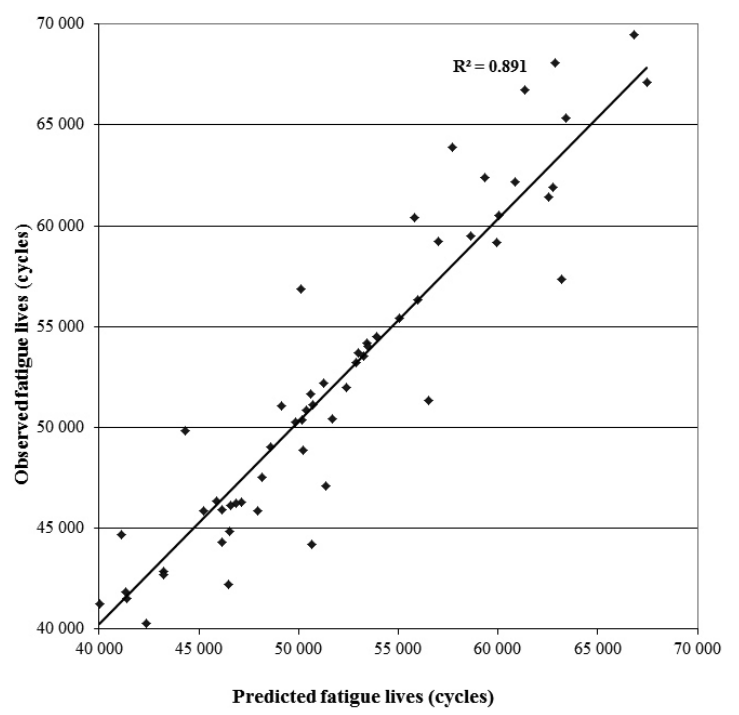

Figure 9. Scattergram of fatigue life prediction model with threehidden layers.

lives compared to calcareous filler specimens. Kangal (C type) and Çayırhan fly ash (F type) specimens have shown approximately $18 \%$ and $9 \%$ longer fatigue lives respectively when compared to those of the calcareous filler specimens. The neural network training and simulation were based on the experimental results of repeated load indirect tensile tests on standard Marshall specimens.

The network topology with the smallest Root Mean Squared Error and the highest coefficient of determination for observed versus predicted data was selected. According to the simulation results, the fatigue lives of the fly ash filler replaced and control specimens were obtained in a very reasonable manner as it is visualized with the scattergrams. For a specific bituminous mixture with the same type of aggregate, gradation, bitumen and testing conditions, it is very reasonable to make the estimations of fatigue lives through the use of artificial neural networks. That means the change of the "physical properties" of a specific bituminous mixture can be modelled using neural networks and considerable time savings can be obtained by eliminating time consuming laboratory testing. This is a major advantage over all the laboratory testing procedures carried worldwide. Determination of fatigue lives of asphalt specimens with repeated load indirect tensile tests is solely a rapid solution. With the aid of artificial neural networks, this effect has been doubled.

By the aid of artificial neural network estimations of fatigue life of asphalt mixtures modified especially by different types of fly ashes (or other modifying agents such as polymers), a pavement engineer can easily estimate the fatigue lives of sections without carrying out on-site analyses and waiting maybe for years and years to arrive at solid conclusions (sometimes it might also be not possible to arrive at these conclusions because of unexpected environmental conditions). Marshall specimens fabricated in the laboratory environment or cores taken from site can be a solution to these intricate analyses by the help of a universal testing machine and an environmental chamber.

The laboratory testing program was carried out by using a single type of aggregate, gradation, bitumen, testing conditions and definite fly ash filler replacers for research purposes so is valid only for the specific laboratory conditions but can be generalised to other types of similar mixtures and testing protocols. For other types of materials and types of mixes, extensive further research should be carried out. These parameters should be changed accordingly and some more testing programs should be developed and carried out, especially for the testing protocols with UMATTA tester. This will form a good basis for further research in order to clarify the effects of different parameters in the estimation of fatigue lives of different types of modified bituminous mixtures by the aid of artificial neural networks. By this way, more insight to the problem of fatigue life estimation of bituminous mixtures by indirect tensile tests can be obtained.

Also other compaction techniques such as gyratory compaction and other fatigue testing protocols from the well-known literature or new equipments can be utilised further to introduce another approach to the problem. One more point is to utilise different gradation types, mixture types and types of filler materials to enrich the subject matter. Finally, to open the black box form of the proposed artificial neural network model, some further studies will be carried out to introduce the artificial neural network application in a closed form solution.

Despite the efforts devoted to the analyses of all of the approaches discussed in this study, there are major areas that still need to be investigated. As back-propagation neural networks have some drawbacks due to the model non-transferability, insufficient ability to generalize, reliance on sigmoid activation functions, their essence as data-driven techniques and finally fluctuations in predicted values, other neural network models should also be used in the analyses, such as radial basis models. 


\section{References}

1. Tapkın S. Improved asphalt aggregate mix properties by Portland cement modification. [Dissertation]. Ankara: Middle East Technical University, Civil Engineering Department, Turkey; 1998.

2. Matthews JM, Monismith CL and Craus J. Investigation of laboratory fatigue testing procedures for asphalt aggregate mixtures. Journal of Transportation Engineering. 1993; 119(4):634-654. http://dx.doi.org/10.1061/(ASCE)0733947X(1993)119:4(634)

3. Kim YR, Lee HJ and Little DL. Fatigue characterization of asphalt concrete using viscoelasticity and continuum damage theory. Journal of the Association of Asphalt Paving Technologists. 1997; 66:520-569.

4. Roque R, Birgisson B, Sangpetngam B and Zhang Z. Hot mix asphalt fracture mechanics: a fundamental crack growth law for asphalt mixtures. Journal of the Association of Asphalt Paving Technologists. 2002; 71:816-827.

5. Shen SH and Carpenter SH. Application of dissipated energy concept in fatigue endurance limit testing. Transportation Research Record. 2005; 1929:165-173. http://dx.doi. org/10.3141/1929-20

6. Shu X, Huang BS and Vukosavljevic D. Laboratory evaluation of fatigue characteristics of recycled asphalt mixture. Construction and Building Materials. 2008; 22(7):1323-1330. http://dx.doi.org/10.1016/j.conbuildmat.2007.04.019

7. Anderson DA, Tarris JP and Brock D. Dust collector fines and their influence on mixture design. Journal of the Association of Asphalt Paving Technologists. 1982; 51:363-374.

8. Ali N, Chan JS, Simms S, Bushman R and Bergan AT. Mechanistic evaluation of fly ash asphalt concrete mixtures. Journal of Materials in Civil Engineering. 1996; 8(1): 19-25. http://dx.doi.org/10.1061/(ASCE)0899-1561(1996)8:1(19)

9. Churchill EV and Amirkhanian SN. Coal ash utilization in asphalt concrete mixtures. Journal of Materials in Civil Engineering. 1999; 11(4):295-301. http://dx.doi.org/10.1061/ (ASCE)0899-1561(1999)11:4(295)

10. Zhao YC, Song LJ and Li GJ. Chemical stabilization of MSW incinerator fly ashes. Journal of Hazardous Materials. 2002; 95(1-2):47-63. http://dx.doi.org/10.1016/S03043894(02)00002-X

11. Fereira C, Ribeiro A and Ottosen L. Possible applications for municipal solid waste fly ash. Journal of Hazardous Materials. 2003; 96(2-3):201-216 http://dx.doi.org/10.1016/ S0304-3894(02)00201-7

12. Mallick RB, Hooper FP, O'Brien S and Kashi M. Evaluation of Use of Synthetic Lightweight Aggregate in Hot-Mix Asphalt. Transportation Research Record. 2004; 1891:1-7. http://dx.doi. org/10.3141/1891-01

13. Wen HF, Tharaniyil MP, Ramme B and Krebs S. Field Performance Evaluation of Class C Fly Ash in Full-Depth Reclamation-Case History Study. Transportation Research Record. 2004; 1869:41-46. http://dx.doi.org/10.3141/1869-05

14. Huang CM, Chiu CT, Li KC and Yang WF. Physical and environmental properties of asphalt mixtures containing incinerator bottom ash. Journal of Hazardous Materials. 2006; 137(3):1742-1749. http://dx.doi.org/10.1016/j. jhazmat.2006.05.016

15. Lin DF, Lin JD and Chen SH. The application of baghouse fines in Taiwan. Resources, Conservation and Recycling. 2006; 46(3):281-301. http://dx.doi.org/10.1016/j. resconrec.2005.08.002

16. Saylak D, Mishra SK, Mejeoumov GG and Shon CS. Fly Ash-Calcium Chloride Stabilization in Road Construction. Transportation Research Record. 2008; 2053:23-29. http:// dx.doi.org/10.3141/2053-04
17. Tapkın S. Mechanical evaluation of asphalt-aggregate mixtures prepared with fly ash as a filler replacement. Canadian Journal of Civil Engineering. 2008; 35(1):27-40. http://dx.doi. org/10.1139/L07-082

18. Xue YJ, Hou HB, Zhu SJ and Zha J. Utilization of municipal solid waste incineration ash in stone mastic asphalt mixture: Pavement performance and environmental impact. Construction and Building Materials. 2009; 23(2):989-996. http://dx.doi. org/10.1016/j.conbuildmat.2008.05.009

19. United States Department of Transportation, Federal Highway Administration. Available from: <http://www.fhwa.dot.gov/ Pavement/recycling/fach01.cfm > Access in: 2013.

20. American Society for Testing and Materials. ASTM Special Publication 91-A. A guide for fatigue testing and the statistical analysis of fatigue data. ASTM; 1963.

21. Wallace K and Monismith CL. Diametral modulus testing on nonlinear pavement materials. Journal of the Association of Asphalt Paving Technologists. 1980; 49:633-652.

22. Whiteoak D. The Shell Bitumen Handbook. Shell Bitumen. United Kingdom; 1990.

23. ELE-UMATTA. Universal materials testing apparatus for asphalt and unbound specimens. Reference and Operating Manual. ELE International Ltd; 1994.

24. Haykin S. Neural Networks. A Comprehensive Foundation. 2nd ed. Prentice Hall; 1999.

25. Tapkın S, Çevik A and Uşar Ü. Accumulated Strain Prediction of Polypropylene Modified Marshall Specimens in Repeated Creep Test Using Artificial Neural Networks. Expert Systems with Applications. 2009; 36(8):11186-11197. http://dx.doi. org/10.1016/j.eswa.2009.02.089

26. Tapkın S, Çevik A and Uşar Ü. Prediction of Marshall test results for polypropylene modified dense bituminous mixtures using neural networks. Expert Systems with Applications. 2010; 37(6):4660-4670. http://dx.doi.org/10.1016/j. eswa.2009.12.042

27. Tapkın S, Çevik A and Özcan Ş. Utilising neural networks and closed form solutions to determine static creep behaviour and optimal polypropylene amount in bituminous mixtures. Materials Research Ibero-American Journal of Materials. 2012; 15(6):865-883. http://dx.doi.org/10.1590/S151614392012005000117

28. Demuth H and Beale M. Neural network toolbox for Use with MATLAB. User's Guide, Version 4. Copyright 1992-2000 by The MathWorks Inc; 2000.

29. General Directorate of Highways of Turkey. Highway Technical Specifications. Item No: 170/2. General Directorate of Highways of Turkey, Ankara, Turkey; 2000.

30. Malvern Instruments Ltd. Mastersizer Series Software Suite, version 2.19 [computer program]. Worcestershire: Malvern instruments Ltd.; 1997.

31. Kim YR, Khosla NP and Kim N. Effect of temperature and mixture variables on fatigue life predicting by diametral fatigue testing. Transportation Research Record. 1991; 1317:128-138.

32. Cabrera JG and Zoorob S. Design of low energy hot rolled asphalt. In Proceedings of the 1st European Symposium; 1994, Leeds. Civil Engineering Materials Unit, Department of Civil Engineering, University of Leeds; 1994. p. 289-308.

33. Tons E, Goetz RO and Razi M. Fly ash as asphalt reducer in bituminous base courses. Project report. Detroit: University of Michigan, the Board of Water and Light, Consumer Power Co., and Detroit Edison Co.; 1983.

34. Tapkın S and Akyılmaz Ö. A new approach to neural trip distribution models: NETDIM. Transportation Planning and Technology. 2009; 32(1):93-114. http://dx.doi. org/10.1080/03081060902750710 